\title{
The Dark Tetrad and aesthetic preferences: The role of the dark side of personality in the aesthetic preference for paintings
}

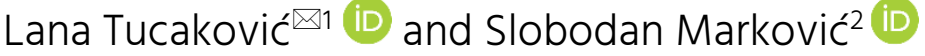 \\ 'Department of Psychology, Faculty of Philosophy, University of Belgrade \\ ${ }^{2}$ Laboratory of Experimental Psychology and Department of Psychology, Faculty of \\ Philosophy, University of Belgrade
}

\section{ABSTRACT}

The role of so-called normal and dark personality traits in everyday preferences, interests, and choices is visible in different domains of life. However, a small number of studies have dealt with individual differences in dark personality traits and aesthetic preferences. The domain of dark personality traits is in recent studies generally conceptualized as the Dark Tetrad - comprised of Machiavellianism, narcissism, psychopathy, and sadism. Thus, the aim of this research was to examine the relationship between the Dark Tetrad and visual aesthetic preferences. The sample consisted of 170 participants $\left(M_{a g e}=29.09\right.$, $S D_{a g e}=10.66 ; 77.1 \%$ females). Participants completed the Short Dark Triad and the Varieties of Sadistic Tendencies questionnaires, and also rated their familiarity and preference for 15 paintings with five different types of motives (religious, abstract, oriental, violence, and landscape). It was shown, based on looking at zero-order correlations that only narcissism positively correlates with the preference for paintings with violent motives. Also, a series of regression analyses were performed, which showed that the only significant regression model is the one that reflects the role of reduced psychopathy in the preference for religious motives. The first finding can be explained on the basis of stable findings on the relationship between narcissism and aggression, and also narcissism and violence. The second finding can be interpreted in the context that general religiosity has previously been shown to be negatively associated with psychopathy. It can be 
concluded that dark personality traits are one of the factors that affect aesthetic preferences.

Keywords: dark personality traits, Dark Tetrad, aesthetic preferences, narcissism, psychopathy

UDC: 159.923.072:111.852

DOI: 10.19090/pp.2021.4. 443-463

Received: 22.04.2021.

Revised: 13.07.2021.

(c) (i)

Copyright (c) 2021 The Author(s).

This is an open access article distributed under the terms of the Creative Commons Attribution License, which permits unrestricted use, distribution, and reproduction in any medium, provided the original author and source are credited.

Accepted: 21.07.2021.

$\bowtie$ Corresponding author e-mail: lana.tucakovic@f.bg.ac.rs 


\section{Introduction}

The role of so-called normal and dark personality traits in everyday preferences, interests, and choices is visible in different domains of life, but only a few studies investigated this role in the field of aesthetic preferences (Bowes et al., 2018). For this reason, one may wonder whether individual differences in personality traits can be determinants of aesthetic preferences or whether aesthetic preferences are shaped only by random aesthetic experiences throughout life (Chamorro-Premuzic et al., 2009; Ercegovac et al., 2015). The dominant approach in examining the relationship between personality traits and art is precisely through the observation of aesthetic preferences, which is usually defined as the degree to which individuals like or dislike certain art movements or styles in visual art (Chamorro-Premuzic et al., 2007). It is assumed that researchers often choose this approach because of the ease of categorizing works of art into different art movements and styles (Chamorro-Premuzic et al., 2007).

According to Marković (2017), aesthetic preference or the experience of beauty-ugliness can be defined as a component of the everyday hedonic experience that is closely related to personal liking - for instance, one can like a particular design of cell phone or dislike Jean Dubuffet's paintings. In addition to aesthetic preference in this broader sense, there is a special aesthetic phenomenon such as the aesthetic experience. It is a qualitatively specific state of consciousness that is characterized by a fascination with artworks, their meaning, and compositional sophistication. In this paper, we will focus on the first meaning of aesthetic preference, such as liking of artworks because it better reflects more basic personal preferences (see Marković, 2017).

Studies of the relationship between normal personality traits (e.g., openness to experience, sensation seeking, etc.) and aesthetic preferences have been done for decades (Burt, 1933; Rawlings et al., 2000). However, during all this time, a small number of studies have dealt with individual differences in dark personality traits and aesthetic preferences (e.g., 
Newberry, 2017). Before we move on to the aim of this research, it will be described what is meant by dark personality traits and the studies that have been done so far in the field of personality traits and aesthetic preferences.

\section{The Dark Tetrad}

Previous studies have used three traits to describe immoral, deceitful, and antisocial individuals, using the unified term 'Dark Triad', namely subclinical narcissism, Machiavellianism, and subclinical psychopathy (Buckels et al., 2013; Međedović \& Bulut, 2017). By narcissism is meant a subclinical version of the personality disorder defined according to the Diagnostic and Statistical Manual of Mental Disorders (DSM) and implies a feeling of superiority, dominance, privilege, grandiosity, high self-esteem, lack of empathy, as well as the need for other people to admire them. The construct Machiavellianism encompasses people who are cold, cynical, manipulative, and people perceive them as charming (Jonason et al., 2012; Paulhus \& Williams, 2002). The central characteristics of psychopathy are the search for excitement, harsh social attitudes, interpersonal antagonism, egocentrism, flattened affect, high impulsivity, low anxiety, low empathy, lack of remorse, etc. (Jonason et al., 2012; Jonason et al., 2014). It was only later that the trait of sadism was added to this set of subclinical personality traits and the name was changed to 'Dark Tetrad' (Buckels et al., 2013; Međedović \& Petrović, 2015). The psychological construct of sadism is broadly defined as experiencing feelings of satisfaction when other people are harassed or hurt (Baumeister \& Campbell, 1999; Bulut, 2017).

\section{Visual aesthetic preference and its relations with} personality

Studies of the relationship between personality traits and artistic preferences have most often used the Big Five model of personality (e.g., Chamorro-Premuzic \& Furnham, 2004; Chamorro-Premuzic et al., 2009; Chamorro-Premuzic et al., 2010). In most studies of this type, it has been shown that the trait of openness to experience plays a role in the formation 
of aesthetic preferences, while other personality traits from the model (extraversion, conscientiousness, agreeableness, and neuroticism) have a greater influence on specific aesthetic preferences (Chamorro-Premuzic et al., 2009; Chamorro-Premuzic et al., 2010). Prior research also often studied links between the trait of sensation seeking and aesthetic preferences (e.g., Rawlings et al., 2000; Tobacyck et al., 1981; Zaleski, 1984; Zuckerman et al., 1993).

Participants with low scores on openness to experience and sensation seeking show a preference for more harmoniously structured (classicist, figural) images. On the other hand, the increase in scores on these traits leads to an increase in the preference for compositionally "chaotic" and more obscure (expressionist, more abstract) paintings (Feist \& Brady, 2004; Furnham \& Avison, 1997; Rawlings, 2000, 2003; Rawlings et al., 2000; Tobacyck et al., 1981; Zaleski, 1984; Zuckerman et al., 1993). Furthermore, studies have shown that the preference for pleasant or unpleasant (violent) artwork was associated with openness to experience and sensation seeking. For the trait of openness to experience, studies suggest that higher openness to experience is related to liking unpleasant (violent) artwork (Rawlings, 2000, 2003). For the relation of sensation seeking and the preference for violent paintings, conflicting findings are obtained, in most studies participants with high scores on the sensation seeking scales like unpleasant, violent paintings (Rawlings, 2000, 2003), while in one study it was shown that participants with a high score on a sensation seeking scale dislike unpleasant and violent paintings (Rawlings \& Bastian, 2002). However, in general, normal personality traits explain a low percentage of variance in aesthetic preferences (Chamorro-Premuzic et al., 2010).

The relationship of personality traits from the Dark Tetrad with aesthetic preferences can be expected due to their association with sensation seeking and personality traits from the Big Five model (Newberry, 2017). Narcissism negatively correlates with agreeableness, while it positively correlates with extraversion, openness, and sensation seeking (Crysel et al., 2013; Paulhus \& Williams, 2002). Machiavellianism is negatively associated with conscientiousness and agreeableness, while it is positively associated 
with sensation seeking (Crysel et al., 2013; Paulhus \& Williams, 2002). Psychopathy is associated with all normal personality traits; it is positively associated with extraversion, openness, and sensation seeking, while it is negatively associated with agreeableness, conscientiousness, and neuroticism (Crysel et al., 2013; Paulhus \& Williams, 2002). Finally, sadism is positively associated with extraversion; while on the other hand, it is negatively associated with conscientiousness, agreeableness, and neuroticism (Book et al., 2016).

In addition to their relationship with normal personality traits, we can expect their relationship with aesthetic preferences due to the fact that they successfully predict preferences in the domain of entertainment (Battista, 2011; Bowes et al., 2018; Williams et al., 2001; Williams et al., 2007). Psychopathy is positively associated with a preference for aggressive and horror movies and rock music, it is negatively associated with a preference for pop music and romantic movies (Battista, 2011; Williams et al., 2001; Williams et al., 2007), while in one study it did not have clear and consistent associations with entertainment preferences (Bowes et al., 2018). Narcissism is not related in a specific manner to movie and music genres, but it showed a positive association with a preference for war and western movies (Bowes et al., 2018). Machiavellianism has been shown to be positively associated with watching aggressive films, albeit to a lesser degree than psychopathy (Williams et al., 2001). So far, the connection between sadism and preferences in the field of entertainment or art has not been investigated.

\section{The present study}

The aim of this research was to examine the relationship between personality and visual aesthetic preferences, more precisely the role that dark personality traits play in the preference for paintings with different main motives. Although previous research has shown that artistic preferences are influenced by stable normal personality traits (e.g., Feist \& Brady, 2004; Furnham \& Avison, 1997; Furnham \& Walker, 2001; Rawlings, 2000, 2003; Rawlings et al., 2000; Tobacyck et al., 1981; Zaleski, 1984; Zuckerman et al., 1993), 
to the best of our knowledge, no study has been conducted on the influence that the Dark Tetrad, as a set of stable dark personality traits, has on the formation of aesthetic preferences and more specifically on the preference for visual motives. We hypothesized that all traits from the Dark Tetrad would show positive associations with the preference for motives of violence in paintings. This was expected based on previous studies which showed that people with higher scores on dark personality traits show a preference for genres of music and movies which contain violent content (Battista, 2011; Bowes et al., 2018; Williams et al., 2001; Williams et al., 2007).

Method

\section{Sample}

The sample consisted of 170 participants, aged 18 to 66 years $\left(M_{\text {age }}=\right.$ 29.09, $S D_{\text {age }}=10.66 ; 77.1 \%$ females). The participants were recruited via snowball method through social media. Participation in the study was on a voluntary basis and without financial compensation. The study was conducted in accordance with the Helsinki Declaration.

Instruments

The Short Dark Triad (SD3)

The Short Dark Triad (SD3; Jones \& Paulhus, 2014). With this scale, personal dispositions towards the dark side of the personality were examined. This scale measures three dark personality traits - Machiavellianism, psychopathy, and narcissism. The scale contains 27 items. It was used in a selfreport form. The participant gives answers on a five-point Likert scale ( $1=$ strongly disagree; 5 = strongly agree). The scores on each of the subscales are obtained by averaging the responses on the items and recoding the inverse items. The psychometric properties of the scale on the sample can be seen in Table 1 in the Results section. 
Varieties of Sadistic Tendencies (VAST)

Varieties of Sadistic Tendencies (VAST; Paulhus \& Jones, 2015). This scale is designed to measure the propensity for sadistic behavior. In the scale, a distinction is made, in the form of subscales, between direct sadism and vicarious sadism. Direct sadism involves enjoying hurting others, either physically or verbally, while vicarious sadism involves enjoying watching others while someone else hurts them. The scale contains 16 items. For the purposes of this study, only the direct sadism subscale, which contains 7 items, was used to merge with the traits from the Dark Triad. The participant gives answers on a five-point Likert scale ( 1 = strongly disagree; 5 = strongly agree). The scores on the subscale are obtained by averaging the answers on the items and recoding the inversely formulated items. The psychometric properties obtained on the sample can be seen in Table 1 in the Results section.

\section{Visual stimuli}

Studies in the field of aesthetic preferences have used different categorizations of visual art and as a result, inconsistent findings are obtained regarding the relationship between aesthetic preferences and personality traits (Ercegovac et al., 2015). One of the pragmatic approaches to the categorization of visual art is the selection of paintings according to their predominant motive, which has been shown to be an important criterion in preferences in the visual domain (Ercegovac et al., 2015). This method of categorization was used in this study. The five categories of motives (Ercegovac et al., 2015) that were presented were religious motives (e.g., The Elevation of the Cross, Peter Paul Rubens), motives of violence (e.g., The Revolt of Cairo, Anne-Louis Girodet de Roussy-Trioson), oriental motives (e.g., Bharat Mata, Abanindranath Tagore), landscape motives (e.g., a painting by Claude Monet from his series Haystacks), and abstract motives (e.g., Blue painting, Wassily Kandinsky). Fifteen art paintings were selected (three paintings for each type of motive). 
Aesthetic judgment

Each painting was shown with a question on a five-point Likert scale that measures the intensity of preference for a certain painting ( $1=$ / don't like it at all; $5=$ / like it very much). Participants were also asked to rate the familiarity of paintings on a five-point Likert scale (1 = not known to me at all; 5 = very familiar to me). Likert-type rating scales were chosen for measuring aesthetic preferences, as a standard way to evaluate paintings in psychology of art (e.g., Ercegovac et al., 2015; Stojilović \& Marković, 2014). Descriptive statistics and psychometric properties for the preference and familiarity of paintings with different motives can be seen in Table 1 in the Results section.

Procedure

Instruments and visual material were placed on the Google Forms platform and distributed via social networks. The time for filling out the questionnaires and aesthetic judgment was not limited, but it took about 15 minutes to complete. Before filling out the questionnaires and aesthetic judgment, the participants gave their consent to participate in the study. After that, they answered a set of questions related to sociodemographic characteristics - gender and age. Participants were shown paintings in a randomized order, with questions related to the familiarity of the painting and the intensity of the preference for the painting. After aesthetic judgment, participants were given questionnaires related to the Dark Tetrad. After completing the questionnaire and aesthetic judgment, the participants were given the opportunity to comment on their impression of the study, as well as the contact e-mail of the researcher if they want to receive feedback on the study. 


\section{Results}

Descriptive statistics and psychometric properties of analyzed measures

Descriptive statistics and psychometric properties of all measures used are given in Table 1. Analysis of aesthetic preferences of different motives showed a significant main effect $(F(4,676)=41.53, p<.01)$, while post hoc analyses showed that there are significant differences between almost all categories of motives, except between landscape and religious motives, as well as oriental and violent motives. It can be concluded that the participants liked the paintings with religious and landscape motives the most, while they liked the abstract paintings the least. Regarding the reliability of the preferences of artistic motives, the highest reliability was obtained for the preference for religious paintings, while the lowest reliability was obtained for the preference for paintings with oriental motives. It can be noticed that the average familiarity of paintings within different categories of motives is low; therefore, most of the artwork shown to the participants were unknown to them. Statistical analyses showed that there is a difference in familiarity between paintings with different motives $(F(4,176)=50.18, p<$ .01). Participants were most familiar with paintings with religious motives, while they were the least familiar with abstract and oriental paintings. Reliabilities are slightly lower for narcissism, psychopathy, and direct sadism compared to results from previous studies (Jones \& Paulhus, 2014; Paulhus \& Jones, 2015). 
Table 1

Descriptive statistics and psychometric properties of all measures used

\begin{tabular}{lccc}
\hline Measure & M(SD) & Min-Max & $\alpha$ \\
\hline Preference for abstract paintings & $7.82(2.76)$ & $3-14$ & .50 \\
Preference for landscape paintings & $10.69(2.60)$ & $3-15$ & .62 \\
Preference for oriental paintings & $9.37(2.58)$ & $3-15$ & .45 \\
Preference for religious paintings & $10.44(3.22)$ & $3-15$ & .81 \\
Preference for violent paintings & $9.11(3.55)$ & $3-15$ & .76 \\
Familiarity with abstract paintings & $6.28(3.28)$ & $3-15$ & .63 \\
Familiarity with landscape paintings & $6.69(3.14)$ & $3-15$ & .64 \\
Familiarity with oriental paintings & $6.06(2.94)$ & $3-15$ & .64 \\
Familiarity with religious paintings & $8.86(3.42)$ & $3-15$ & .52 \\
Familiarity with violent paintings & $7.08(3.21)$ & $3-15$ & .61 \\
Machiavellianism & $2.94(.69)$ & $1-5$ & .74 \\
Narcissism & $2.71(.67)$ & $1-5$ & .68 \\
Psychopathy & $1.85(.64)$ & $1-4$ & .71 \\
Direct sadism & $1.66(.54)$ & $1-4$ & .55 \\
\hline
\end{tabular}

Notes: $M$ - mean; $S D$ - standard deviation; Min-Max - minimum and maximum; $\alpha-$ Cronbach's alpha.

Relationship between aesthetic preferences of different motives and the Dark Tetrad

In order to get a preliminary insight into the association between aesthetic preferences of different motives and the Dark Tetrad, as well as intercorrelations of aesthetic preferences of different motives and the Dark Tetrad, Pearson correlation coefficients were calculated, which can be seen in Table 2. Based on Table 2, it can be observed that significant positive correlations were obtained between the preferences of all types of motives, except between the preferences of abstract and religious motives. It was obtained that the traits of the Dark Tetrad are low to highly correlated, which is in line with the findings from previous studies (e.g., Chabrol et al., 2017). Regarding the relation between aesthetic preferences and the Dark Tetrad, 
only a low positive correlation was obtained between narcissism and the preference for violent motives in the paintings.

\section{Table 2}

Pearson bivariate correlations between aesthetic preferences and the Dark Tetrad

\begin{tabular}{llllllllll}
\hline Measure & 1 & 2 & 3 & 4 & 5 & 6 & 7 & 8 & 9 \\
\hline
\end{tabular}

1. Preference for abstract paintings -

2. Preference for landscape paintings $.42^{\text {** }}$ -

3. Preference for religious paintings $.14 \quad .26^{* *}$ -

4. Preference for oriental paintings $.37^{* *} .49^{* *} .42^{* *}$ -

5. Preference for violent paintings $\quad .30^{* *} .33^{* *} .70^{* *} \cdot 53^{* *}-$

6. Machiavellianism $\quad \begin{array}{lllllll}0.07 & -.03 & .09 & .04 & .09 & -\end{array}$

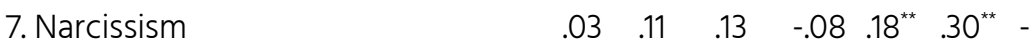

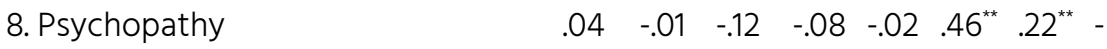

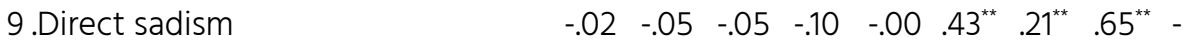

Note: ${ }^{* *} p<.01$.

In order to see in more detail, the role of the Dark Tetrad in aesthetic preferences, a series of regression analyses were performed, where the traits of the Dark Tetrad were predictors, and the aesthetic preferences of different motives were criteria and analyses results can be seen in Table 3. The only significant regression model is the one in which the criterion variable is the aesthetic preference for religious motives, where psychopathy stands out as the only significant predictor and explains $6 \%$ of the variance, while in the statistically insignificant regression model, narcissism stands out, as seen in the correlation analysis, as a predictor of the preference for religious motives. 
Table 3

Results (standardized regression coefficients, coefficients of multiple correlation, and percent of explained variance) of standard regression analyses with aesthetic preferences as criteria

\begin{tabular}{|c|c|c|c|c|c|}
\hline & & & $\begin{array}{l}\text { Aesthetic } \\
\text { preferences }\end{array}$ & & \\
\hline The Dark Tetrad & $\begin{array}{c}\text { Preference } \\
\text { for } \\
\text { abstract } \\
\text { paintings }\end{array}$ & $\begin{array}{c}\text { Preference } \\
\text { for } \\
\text { landscape } \\
\text { paintings }\end{array}$ & $\begin{array}{l}\text { Preference } \\
\text { for religious } \\
\text { paintings }\end{array}$ & $\begin{array}{l}\text { Preference } \\
\text { for } \\
\text { oriental } \\
\text { paintings }\end{array}$ & $\begin{array}{c}\text { Preference } \\
\text { for violent } \\
\text { paintings }\end{array}$ \\
\hline Machiavellianism & -.11 & -.05 & .16 & .14 & .08 \\
\hline Narcissism & .05 & .14 & .14 & -.08 & $.18^{* *}$ \\
\hline Psychopathy & .11 & .03 & $-.22^{\star *}$ & -.06 & -.08 \\
\hline Direct sadism & -.05 & -.08 & .00 & -.11 & -.03 \\
\hline$R$ & .12 & .14 & .24 & .17 & .21 \\
\hline$R^{2}$ & .02 & .02 & .06 & .03 & .04 \\
\hline$F(4)$ & .62 & .88 & $2.61^{\star \star}$ & 1.18 & 1.85 \\
\hline
\end{tabular}

Note: ${ }^{* *} p<.01$.

\section{Discussion and Conclusion}

\section{Visual aesthetic preferences}

The analysis of aesthetic preferences showed that the participants preferred paintings with landscape and religious motives, while they expressed the lowest preferences for paintings with abstract motives. Additionally, it has been shown on the basis of correlations between preferences, that there is some kind of general preference for paintings regardless of the presented motive. This has been shown in almost all cases, except there was an absence of correlation between the preferences of abstract and religious motives. The preference for landscape paintings is understandable based on the results from previous research and can be explained by the universal preference for landscapes discovered by Komar and Melamid (1999), while the finding that paintings with religious motives 
are also highly preferred is contrary to their previous findings. Landscape preference could also be explained by the greater presence of landscape paintings in people's daily lives compared to other examined motives (Ercegovac et al., 2015). Another potential explanation is that by being more present than other motives, that they are also a more socially desirable preference and that the results obtained are such due to the response style of the participants (Ercegovac et al., 2015). An additional interpretation of this finding is that artworks containing landscapes are created so that they can be processed in a way that relates to the coding of natural stimuli, for which the human visual system is highly adapted (Redies, 2015). More precisely, people prefer landscape paintings because they mimic natural scenes (Redies, 2015). The finding regarding religious preference may be explained by the idea that religious art evokes strong emotions, which are contained within the narrative of the art piece (Yanulevskaya et al., 2012). The lowest preference for abstract paintings is in line with cross-cultural findings on the aversion to unusual, abstract paintings versus realistic paintings (Komar \& Melamid, 1999).

Visual aesthetic preferences and its relations with dark personality traits

Previous research has shown that normal personality traits are associated with aesthetic preferences (e.g., Chamorro-Premuzic \& Furnham, 2004; Chamorro-Premuzic et al., 2009; Chamorro-Premuzic et al., 2010; Ercegovac et al., 2015; Feist \& Brady, 2004). In this study, it was shown based on looking at zero-order correlations that only narcissism positively correlates with the preference for paintings with violent motives. This finding can be explained by a finding of similar type that people with higher narcissism prefer to watch westerns and war movies in which scenes of violence are frequent (Bowes et al., 2018). The finding can also be explained on the basis of stable findings on the association between narcissism and aggression, as well as narcissism and violence (Lambe et al., 2018). The tendency towards aggression and violence in narcissistic people is explained to exist in situations where there is an ego threat (Lambe et al., 2018). 
When observing the group role of dark personality traits in the aesthetic preferences of different motives, the only significant regression model is the one that reflects the role of reduced psychopathy in the preference for religious motives. This finding can be interpreted in the context that general religiosity has been shown to be negatively associated with psychopathy, which is assumed to be, among other things, due to the fact that persons who have high scores on dark personality traits also have low scores on measures of empathy (Łowicki \& Zajenkowski, 2017). The absence of an association between the Dark Tetrad and the preferences of other categories of motives can be explained by the fact that individual differences in personality traits do not significantly predict preference for certain types of stimuli, as shown by research with personality traits from the Big Five model (Swami \& Furnham, 2014).

\section{Limitations}

One of the limitations of this study was the difference in the familiarity of paintings belonging to the categories of different motives, but considering that it was not a variable of interest in this study, it is assumed that it did not affect the main findings related to the association between the Dark Tetrad and aesthetic preferences. It would certainly be useful in future studies to try to determine the prevalence of familiarity for paintings with different motives in the Serbian population. A more heterogeneous sample in terms of gender in future studies could shed more light on the relationship between the Dark Tetrad and aesthetic preferences, due to the fact that men typically score higher on the Dark Tetrad (Jones \& Paulhus, 2014). Additional knowledge would be brought to us by studies that include the so-called normal and dark sides of personality, by using the Big Five model and the Dark Tetrad model.

\section{Conflict of interest}

We have no conflicts of interest to disclose. 
Data availability statement

The dataset linked to this research was not deposited in any of the data repositories; however, it can be obtained by contacting the corresponding author.

\section{References}

Battista, M. E. (2011). Does Anyone Really Like Horror Movies? Personality and Automatic Affective Reactions to Frightening Films. (Doctoral dissertation, The University of Western Ontario, London, Ontario, Canada). Retrieved (April, 2021) from:

https://ir.lib.uwo.ca/cgi/viewcontent.cgi?article=1174\&context=etd

Baumeister, R. F., \& Campbell, W. K. (1999). The intrinsic appeal of evil: Sadism, sensational thrills, and threatened egotism. Personality and Social Psychology Review, 3(3), 210-221.

https://doi.org/10.1207/s15327957pspr0303_4

Book, A., Visser, B. A., Blais, J., Hosker-Field, A., Methot-Jones, T., Gauthier, N. Y., ... \& D'Agata, M. T. (2016). Unpacking more "evil": What is at the core of the dark tetrad?. Personality and Individual Differences, 90, 269-272. https://doi.org/10.1016/.jpaid.2015.11.009

Bowes, S. M., Watts, A. L., Costello, T. H., Murphy, B. A., \& Lilienfeld, S. O. (2018). Psychopathy and entertainment preferences: Clarifying the role of abnormal and normal personality in music and movie interests. Personality and Individual Differences, 129, 33-37. https://doi.org/10.1016/j.paid.2018.03.009

Buckels, E. E., Jones, D. N., \& Paulhus, D. L. (2013). Behavioral confirmation of everyday sadism. Psychological science, 24(11), 2201-2209. https://doi.org/10.1177/0956797613490749

Bulut, T. (2017). The concept of sadism in the current empirical literature. Zbornik Instituta za kriminološka i sociološka istraživanja, 36, 23-41. 
Burt, C. (1933). The psychology of art. In C. Burt, E. Jones, \& W. Moodie (Eds.), How the mind works (chap. 15). London: Allen and Unwin.

Chabrol, H., Bouvet, R., \& Goutaudier, N. (2017). The Dark Tetrad and antisocial behavior in a community sample of college students. Journal of forensic psychology research and practice, 175), 295-304.

https://doi.org/10.1080/24732850.2017.1361310

Chamorro-Premuzic, T., \& Furnham, A. (2004). Art judgment: a measure related to both personality and intelligence?. Imagination, Cognition and Personality, 24(1), 3-24. https://doi.org/10.2190/U4LW-TH9X-80M3-NJ54

Chamorro-Premuzic, T., Burke, C., Hsu, A., \& Swami, V. (2010). Personality predictors of artistic preferences as a function of the emotional valence and perceived complexity of paintings. Psychology of Aesthetics, Creativity, and the Arts, 4(4), 196-204. https://doi.org/10.1037/a0019211

Chamorro-Premuzic, T., Furnham, A., \& Reimers, S. (2007). The ARTistic. Psychologist, 20(2), 84-87.

Chamorro-Premuzic, T., Reimers, S., Hsu, A., \& Ahmetoglu, G. (2009). Who art thou? Personality predictors of artistic preferences in a large UK sample: The importance of openness. British Journal of Psychology, 100(3), 501516. https://doi.org/10.1348/000712608X366867

Crysel, L. C., Crosier, B. S., \& Webster, G. D. (2013). The Dark Triad and risk behavior. Personality and individual differences, 54(1), 35-40. https://doi.org/10.1016/.jpaid.2012.07.029

Ercegovac, I. R., Dobrota, S., \& Kuščević, D. (2015). Relationship between music and visual art preferences and some personality traits. Empirical Studies of the Arts, 33(2), 207-227. https://doi.org/10.1177/0276237415597390

Feist, G. J., \& Brady, T. R. (2004). Openness to experience, non-conformity, and the preference for abstract art. Empirical Studies of the Arts, 22(1), 7789. https://doi.org/10.2190/y7ca-tby6-v7lr-76gk 
Furnham, A. \& Avison, M. (1997). Personality and preference for surrealistic paintings. Personality and Individual Differences, 23, 923-935. https://doi.org/10.1016/s0191-8869(97)00131-1

Furnham, A., \& Walker, J. (2001). The influence of personality traits, previous experience of art, and demographic variables on artistic preference. Personality and Individual Differences, 31(6), 997-1017. https://doi.org/10.1016/S0191-8869(00)00202-6

Jonason, P. K., Lyons, M., \& Bethell, E. (2014). The making of Darth Vader: Parentchild care and the Dark Triad. Personality and Individual Differences, 67, 30-34. https://doi.org/10.1016/j.paid.2013.10.006

Jonason, P. K., Webster, G. D., Schmitt, D. P., Li, N. P., \& Crysel, L. (2012). The antihero in popular culture: Life history theory and the dark triad personality traits. Review of General Psychology, 16(2), 192-199. https://doi.org/10.1037/a0027914

Jones, D. N., \& Paulhus, D. L. (2014). Introducing the short dark triad (SD3) a brief measure of dark personality traits. Assessment, 27(1), 28-41. https://doi.org/10.1177/1073191113514105

Komar, V., \& Melamid, A. (1999). Painting by numbers: Komar and Melamid's scientific guide to art. University of California Press.

Lambe, S., Hamilton-Giachritsis, C., Garner, E., \& Walker, J. (2018). The role of narcissism in aggression and violence: A systematic review. Trauma, Violence, \& Abuse, 19(2), 209-230.

\section{https://doi.org/10.1177/1524838016650190}

Łowicki, P., \& Zajenkowski, M. (2017). No empathy for people nor for God: The relationship between the Dark Triad, religiosity and empathy. Personality and Individual Differences, 115, 169-173. https://doi.org/10.1016/i.paid.2016.02.012

Marković S. (2017). Domeni estetske preferencije. Od estetskog stimulusa do estetskog doživljaja. [Domains of aesthetic preference. From aesthetic stimulus to aesthetic experience]. Beograd: Dosije studio. 
Međedović, J., \& Bulut, T. (2017). Expanding the nomological network of Dark Tetrad: The case of cynicism, aggressive humor and attitudes towards immigrants. Zbornik Instituta za kriminološka i sociološka istraživanja, 36, 7-19.

Međedović, J., \& Petrović, B. (2015). The Dark Tetrad: Structural properties and location in the personality space. Journal of Individual Differences, 36(4), 228-236. https://doi.org/10.1027/1614-0001/a000179

Newberry, M. (2017, May). Darkness and light: the role of dark triad traits and empathy in understanding preferences for visual artworks. Paper presented at the 11th Annual International Conference on Psychology, Athens, Greece.

Paulhus, D. L., \& Jones, D. N. (2015). Measures of dark personalities. In Measures of personality and social psychological constructs (pp. 562-594). Academic Press. https://doi.org/10.1016/B978-0-12-386915-9.00020-6

Paulhus, D. L., \& Williams, K. M. (2002). The dark triad of personality: Narcissism, Machiavellianism, and psychopathy. Journal of research in personality, 36(6), 556-563. https://doi.org/10.1016/S00926566(02)00505-6

Rawlings, D. (2000). The interaction of openness to experience and schizotypy in predicting preference for abstract and violent paintings. Empirical Studies of the Arts, 18, 69-91. https://doi.org/10.2190/71ct-aa49-xrmg$\underline{\mathrm{c} 842}$

Rawlings, D. (2003). Personality correlates of liking for 'unpleasant' paintings and photographs. Personality and Individual Differences, 34, 395-410. https://doi.org/10.1016/s0191-8869(02)00062-4

Rawlings, D., \& Bastian, B. (2002). Painting preference and personality, with particular reference to Gray's behavioral inhibition and behavioral approach systems. Empirical Studies of the Arts, 20(2), 177-193. https://doi.org/10.2190/73uq-50qu-uatw-ry5e 
Rawlings, D., Barrantes-Vidal, N. \& Furnham, A. (2000). Personality and aesthetic preference in Spain and England: Two studies relating sensation seeking and openness to experience to liking for paintings and music. European Journal of Personality, 14, 553-576. https://doi.org/10.1002/10990984(200011/12)14:6<553::aid-per384>3.0.c0;2-h

Redies, C. (2015). Combining universal beauty and cultural context in a unifying model of visual aesthetic experience. Frontiers in human neuroscience, 9, 218. https://doi.org/10.3389/fnhum.2015.00218

Stojilović, I. Z., \& Marković, S. (2014). Evaluation of paintings: Effects of lectures. Psihologija, 474), 415-432. https://doi.org/10.2298/PSI1404415S

Swami, V., \& Furnham, A (2014). Personality and aesthetic experiences. In P. Tinio \& J. Smith (Eds.), Cambridge handbook of the psychology of aesthetics and the arts. Cambridge, UK: Cambridge University Press.

Tobacyck., J. J., Myers, H. \& Bailey, L. (1981). Field dependence, sensation seeking and preference for paintings. Journal of Personality Assesment, 45, 270277. https://doi.org/10.1207/s15327752jpa4503_8

Williams, K. M., McAndrew, A., Learn, T., Harms, P., \& Paulhus, D. L. (2001, August). The Dark Triad returns: Entertainment preferences and antisocial behavior among narcissists, Machiavellians, and psychopaths. Poster presented at the 109th Annual Convention of the American Psychological Association, San Francisco, CA.

Williams, K. M., Paulhus, D. L., \& Hare, R. D. (2007). Capturing the four-factor structure of psychopathy in college students via self-report. Journal of personality assessment, 88(2), 205-219.

https://doi.org/10.1080/00223890701268074

Yanulevskaya, V., Uijlings, J., Bruni, E., Sartori, A., Zamboni, E., Bacci, F., Melcher, D., \& Sebe, N. (2012). In the eye of the beholder: employing statistical analysis and eye tracking for analyzing abstract paintings. In Proceedings of the 20th ACM international conference on Multimedia, 349-358. https://doi.org/10.1145/2393347.2393399 
Zaleski, Z. (1984). Sensation seeking and preference for emotional visual stimuli. Personality and Individual Differences, 5, 609-611. https://doi.org/10.1016/0191-8869(84)90040-0

Zuckerman, M., Ulrich, R. S. \& McLaughlin, J. (1993). Sensation seeking and reactions to nature paintings. Personality and Individual Differences, 15, 563-576. https://doi.org/10.1016/0191-8869(93)90340-9 
